Brazilian Journal

of Chemical

ISSN 0104-6632

Engineering

\title{
EXPERIMENTAL DATA, THERMODYNAMIC MODELING AND SENSITIVITY ANALYSES FOR THE PURIFICATION STEPS OF ETHYL BIODIESEL FROM FODDER RADISH OIL PRODUCTION
}

\author{
R. C. Basso ${ }^{1 *}$, A. J. de A. Meirelles ${ }^{2}$ and E. A. C. Batista ${ }^{2}$ \\ ${ }^{1}$ Institute of Science and Technology, (Campus de Poços de Caldas), Federal University of Alfenas, \\ (Unifal-MG), CEP: 37715-400, Poços de Caldas - MG, Brazil. \\ ${ }^{2}$ Laboratory of Extraction, Applied Thermodynamics and Equilibrium (ExTrAE), School of Food Engineering, \\ Department of Food Engineering, University of Campinas (UNICAMP), CEP: 13083-862, Campinas - SP, Brazil. \\ Phone: + 553588103519 \\ E-mail: rodrigo.c.basso@gmail.com
}

(Submitted: November 28, 2014 ; Revised: September 15, 2015 ; Accepted: September 17, 2015)

\begin{abstract}
The goals of this work were to present original liquid-liquid equilibrium data of the system containing glycerol + ethanol + ethyl biodiesel from fodder radish oil, including the individual distribution of each ethyl ester; to adjust binary parameters of the NRTL; to compare NRTL and UNIFAC-Dortmund in the LLE representation of the system containing glycerol; to simulate different mixer/settler flowsheets for biodiesel purification, evaluating the ratio water/biodiesel used. In thermodynamic modeling, the deviations between experimental data and calculated values were $0.97 \%$ and $3.6 \%$, respectively, using NRTL and UNIFAC-Dortmund. After transesterification, with 3 moles of excess ethanol, removal of this component until a content equal to 0.08 before an ideal settling step allows a glycerol content lower than $0.02 \%$ in the ester-rich phase. Removal of ethanol, glycerol and water from biodiesel can be performed with countercurrent mixer/settler, using $0.27 \%$ of water in relation to the ester amount in the feed stream.

Keywords: Liquid-liquid equilibrium; Biodiesel purification; Sensitivity analysis; NRTL model.
\end{abstract}

\section{INTRODUCTION}

The chemical transformation of lipid feedstock to biodiesel involves the transesterification of glyceride species with alcohol to alkyl esters (Lotero et al., 2005). This is an equilibrium reaction in which the presence of a catalyst considerably accelerates adjustment of the equilibrium and, in order to achieve a high ester yield, the alcohol is used in excess (Schuchardt et al., 1998). Alternatives to this process are enzymatic processes, requiring preferably low molar alcohol:oil ratios (Akoh et al., 2007), acid catalysis and alcohols in supercritical conditions that use high molar alcohol:oil ratios ranging from 12:1 to 50:1 instead of 6:1 used in the traditional alkaline reaction (Sawangkeau et al., 2011; Zhang et al., 2003). In addition to vegetable oils and fats, it is feasible to use several low cost byproducts from the oil chemical industry for biodiesel production, such as deodorizer fatty acid distillates, soapstocks and acid oils (PilotoRodriguez et al., 2014).

The advantages of using ethanol in biodiesel production include higher miscibility with vegetable oils that allows better contact in the reaction step and lower toxicity. In addition, the use of ethanol in biodiesel synthesis is appealing because it is produced

*To whom correspondence should be addressed 
only from biorenewable sources (Encinar et al., 2002; Stamenkovik et al., 2011). In recent years several different technologies have been considered to optimize ethyl biodiesel production (Valle et al., 2010; Kanitkar et al., 2011; Zhang et al., 2012). Considering the oil source for biodiesel production, the chemical composition of fodder radish (Raphanus sativus) oil, its agricultural characteristics and ester physical properties make this oil an interesting alternative for biodiesel production (Domingos et al., 2008; Crusciol et al., 2005).

After the transesterification reaction, glycerol is separated by settling or centrifuging, forming two different phases, an ester-rich phase (EP) and a glycerolrich phase (GP). In the sequence of this separation step, EP is purified before being used as a biofuel (Atadashi et al., 2011; Berrios and Skelton, 2008). The biodiesel standards requirements for the final content of the three major compounds related to biodiesel synthesis and purification, glycerol, alcohol and water, are $0.02 \%, 0.2 \%$ and $0.05 \%$, respectively.

Water washing is one of the first steps and the most common method for purification of the EP in the production of this biofuel (Saleh et al., 2011). This process can reduce alcohol and free glycerol levels to contents lower than the biodiesel standard quality requirements and can be efficiently carried out at ambient temperature, because this is the most economical condition for biodiesel purification (Atadashi et al., 2011; Berrios and Skelton, 2008). Other alternative methods such as biodiesel purification by cation-exchange resin and by ceramic membrane could not achieve the biodiesel standard requirements without an additional water washing process (Dias et al., 2014). Glisic and Skala (2009), studying the design and optimization of the purification procedure using water washing, observed that for complete removal of $\mathrm{NaOH}$ from the EP, a multistep water washing must be used. In the water washing step, two immiscible phases are formed, one EP and one water-rich phase (WP), where the alcohol distributes in both phases. The design analysis of this step must be judiciously performed since there is a phase inversion in which WP is found in the upper phase and EP in the lower phase, depending on the amount of ethanol in the system (Basso et al., 2014). At the end of this process the residual water must be present at contents lower than $0.02 \%$, and, for this purpose some author reporting the use of hydrogel adsovents (Fregolente et al., 2015) and other technics.

The knowledge of liquid-liquid equilibrium (LLE) in systems containing the major compounds involved in the synthesis and purification steps of biodiesel production is essential for proper design analysis and simulation of these steps. Pisarello et al. (2010) have studied LLE in the reacting systems involved in the acid catalysis for biodiesel production evaluating the influence of the composition on the phase splitting. Other research groups, studying LLE in the purification steps, have evaluated the LLE of systems containing alcohol, biodiesel or alkyl esters, glycerol or water (Liu et al., 2008; Beneti et al., 2010), modeled them using thermodynamic models with association parameters (Barreau et al., 2010; Oliveira et al., 2011; Andreatta et al., 2008) or using classical thermodynamic molecular models (Mesquita et al., 2011; Casas et al., 2014). In addition, some works compared molecular models with predictive models in relation to description of the LLE for this type of system (Lee et al., 2010).

Despite the rise in this type of experimental data, there is little data on systems containing ethyl biodiesels with long chain esters, and only two works in the scientific literature have quantified the individual distribution of fatty acid alkyl esters in both phases (Basso et al., 2012; Basso et al., 2013) which really proves the pseudo-component concept in the LLE behavior for systems containing biodiesel and allows actual analysis of multi-component systems by group contribution models without additional assumptions. Furthermore, there is a lack of studies simulating the biodiesel purification steps using only adjusted parameters, which allows for much more reliable results than predictive models, the most commonly used models. Additionally, although sensitivity analysis is an interesting method to evaluate the impact of different stream compositions and process conditions in biodiesel production steps, it has not been used in the analysis of settling and washing water in ethyl biodiesel production in previous studies. Although it is known that liquid-liquid extraction processes in countercurrent are more efficient than in crosscurrent, there are no works in the literature quantifying the differences between them in biodiesel purification.

Therefore, the goals of this work are to present original LLE data for a system composed of glycerol + ethanol + fatty acid ethyl esters (FAEE) from fodder radish oil at $298.2 \mathrm{~K}$, including the individual distribution of each ethyl ester; to adjust the parameters of the NRTL model from these data; to compare NRTL and UNIFAC-Dortmund (UNIFAC-DRTM) in the representation of the LLE of the system glycerol + ethanol + ethyl biodiesel from fodder radish oil; to describe the biodiesel purification steps by sensitivity analyses using the NRTL model in three different flowsheets, evaluating the water amount used to achieve the biodiesel standard requirements. 


\section{MATERIALS AND METHODS}

\section{Experimental Procedure}

\section{Material}

The crude fodder radish oil was extracted from seeds supplied by Sementes Pirai (Piracicaba, SP, Brazil), using a pilot expeller, and filtered for the removal of fibers from the seeds.

Crude oil was neutralized with a sodium hydroxide solution prior to biodiesel production.

Glycerol (Sigma, $>0.99$; water $<0.003$ ), ethanol (Merck, > 0.999), methanol (J. T. Baker, 0.999), anhydrous sodium hydroxide (Carlo Erba, > 0.97), ethyl myristate (Tecnosyn, $>0.99$ ) and glacial acetic acid (Ecibra, $>0.997$ ) were used in the diverse stages of this work with no further purification.

\section{Biodiesel Production}

Biodiesel from fodder radish oil was produced using sodium hydroxide ( $1 \%$ in relation to vegetable oil weight) dissolved, prior to the reaction, in anhydrous ethanol agitated by a magnetic stirrer. The molar ratio oil:ethanol was $1: 6$, based on average molar mass of triacylglycerols in fodder radish oil. During $60 \mathrm{~min}$ the reagent mixture was kept under agitation at room temperature before being stopped by addition of glacial acetic acid. The resulting mixture was transferred to a separatory funnel for glycerol decanting and for washings (at least five) with hot deionized water until neutral $\mathrm{pH}$. This product was dried under agitation, heating $(333 \mathrm{~K})$ and vacuum $(5 \mathrm{mmHg})$.

Biodiesel was distilled, under vacuum of $2.25 \mathrm{mmHg}$ and temperature of $508.15 \mathrm{~K}$, for separation between fatty acid ethyl esters and possible residual impurities such as acylglycerols that had not reacted, according to the procedure reported by Basso et al. (2012).

\section{LLE Experiments}

LLE data of the systems were determined using sealed headspace glass tubes $(20 \mathrm{~mL})$ (Perkin Elmer), according to the procedure developed by Basso et al. (2012). Two clear layers and a well-defined interface were formed when the systems reached the equilibrium state, the upper layer being the $\mathrm{EP}$, and the lower layer the GP.

\section{Analytical Methodology}

Ethyl biodiesel from fodder radish oil was previously characterized in triplicate to obtain the fatty acid ethyl ester profile using a Perkin Elmer gas chromatographic system, Clarus 600, FID detector, with a Agilent capillary column (crossbond, 50\% cyanopropyl phenyl $-50 \%$ dimethylpolysiloxane), length of 30 $\mathrm{m}$, internal diameter of $0.25 \mathrm{~mm}$ and film thickness of $0.25 \mu \mathrm{m}$, using the analytical conditions described by Basso et al. (2012).

Quantifications of glycerol, individual fatty acid ethyl esters and ethanol in each equilibrium phase were determined at least in triplicate using the same chromatographic system (including the column) used for the characterization of ethyl biodiesel. The analytical conditions were based on the methodology described by Basso et al. (2012) for this type of system. This methodology requires an intermediate polarity column, and several temperature and carrier gas flow ramps to separate the different component classes and the individual fatty acid ethyl esters.

Components of each chemical class in the LLE phases were quantified by different calibration curves.

\section{Calculation Approach}

\section{Calculations of Deviations in The Mass Balance of the Phases}

Validity of the equilibrium experiments was evaluated according to the procedure developed by Marcilla et al. (1995) and applied by Rodrigues et al. (2005). In this procedure the sum of the calculated masses of both liquid phases is compared with the actual value for total mass used in the experiment. In this approach, independent component balances, totaling $\mathrm{K}$ balances, can be performed according to Equation (1):

$\mathrm{M}^{\mathrm{OC}} \mathrm{w}_{\mathrm{i}}^{\mathrm{OC}}=\mathrm{M}^{\mathrm{EP}} \mathrm{w}_{\mathrm{i}}^{\mathrm{EP}}+\mathrm{M}^{\mathrm{GP}} \mathrm{w}_{\mathrm{i}}^{\mathrm{GP}}$

where $\mathrm{i}$ represents each component of the system; $\mathrm{M}^{\mathrm{OC}}$ is the mass of the overall composition; $\mathrm{M}^{\mathrm{GP}}$ and $\mathrm{M}^{\mathrm{EP}}$ are the total masses of the GP and EP, respectively; $\mathrm{w}_{\mathrm{i}}^{\mathrm{OP}}$ is the mass fraction of component $\mathrm{i}$ in the overall composition; $\mathrm{w}_{\mathrm{i}}^{\mathrm{GP}}$ and $\mathrm{w}_{\mathrm{i}}^{\mathrm{EP}}$ are the mass fractions of component $i$, respectively, in the GP and EP.

Thus, the values for $\mathrm{M}^{\mathrm{GP}}$ and $\mathrm{M}^{\mathrm{EP}}$ which minimize the deviations of the system can be found. The sum of $\mathrm{M}^{\mathrm{GP}}$ and $\mathrm{M}^{\mathrm{EP}}$ can be compared to $\mathrm{M}^{\mathrm{OC}}$ and the overall mass balance deviation calculated by:

$\delta(\%)=100 \cdot \frac{\left|\left(\mathrm{M}^{\mathrm{GP}}+\mathrm{M}^{\mathrm{PE}}\right)-\mathrm{M}^{\mathrm{OC}}\right|}{\mathrm{M}^{\mathrm{OC}}}$ 


\section{Calculation of Experimental Uncertainty}

The uncertainty of experimental data for each component in each phase per tie line was calculated from the standard deviation of the mean from the total number of chromatographic injections for each experimental point, performed at least in triplicate, as:

$$
\mathrm{u}\left(\mathrm{x}_{\mathrm{i}}\right)=\sqrt{\frac{1}{\mathrm{n}(\mathrm{n}-1)} \sum_{\mathrm{k}=1}^{\mathrm{n}}\left(\mathrm{X}_{\mathrm{i}, \mathrm{k}}-\overline{\mathrm{X}}_{\mathrm{i}}\right)^{2}}
$$

where $X_{i, k}$ is the concentration of component $i ; n$ is the number of chromatographic injections and $\bar{X}_{i}$ is the mean of the concentration.

The maximum combined uncertainty, used as reference for the uncertainty of the experimental data in this work, was obtained from the maximum value of the combined uncertainty calculated for each phase per tie line considering the concentrations of glycerol, ethanol and biodiesel in each experimental point as:

$\mathrm{u}_{\mathrm{c}}=\sqrt{\mathrm{u}\left(\mathrm{x}_{1}\right)^{2}+\mathrm{u}\left(\mathrm{x}_{2}\right)^{2}+\mathrm{u}\left(\mathrm{x}_{3}\right)^{2}}$

where $u\left(x_{1}\right) ; u\left(x_{2}\right) ; u\left(x_{3}\right)$ are the uncertainties for glycerol, ethanol and biodiesel in each experimental point.

\section{Thermodynamic Modeling}

The experimental data measured for the system glycerol (1) + ethanol (2) + FAEE from fodder radish oil (3) presented in this work were used to adjust binary interaction parameters for the NRTL and the experimental data presented by Basso et al. (2014) for the system water (4) + ethanol (2) + FAEE from fodder radish oil (3) were used to readjust binary interaction parameters for the same model for use in the simulation of biodiesel purification by sensitivity analyses. The sets of parameters were used in the commercial simulator software AspenPlus (Aspen Technology). The ethyl esters were considered individually using the UNIFAC-Dortmund model (UNIFAC-DRTM). When the NRTL model was used, the mixture of fatty acid ethyl esters was treated as a single ethyl ester with a molecular structure that presents the average molar mass of the ethyl ester mixture. In the assembly of the hypothetical molecule structure, the number of each group, obtained according to UNIFAC groups present in each ethyl ester molecule, was weighted by its molar fraction and rounded to the closest integer number. Thus, adjustments were made considering the systems as pseudo-ternary. All binary interaction parameters were adjusted to the experimental data.

The mass fraction (w) was used as a composition unit due to the differences in molar masses of the system components (Oish and Prausnitz, 1978). In this way, the isoactivity criterion of the LLE developed on a molar fraction basis can be expressed on a mass fraction basis as:

$$
\left(\gamma_{i} x_{i}\right)^{I}=\left(\gamma_{i} x_{i}\right)^{I I}
$$

$\left(\gamma_{i}^{\mathrm{W}} \mathrm{w}_{\mathrm{i}}\right)^{\mathrm{I}}=\left(\gamma_{\mathrm{i}}^{\mathrm{W}} \mathrm{w}_{\mathrm{i}}\right)^{\mathrm{II}}$

where:

$$
\gamma_{i}^{\mathrm{w}}=\frac{\gamma_{\mathrm{i}}}{\mathrm{M}_{\mathrm{i}} \sum_{\mathrm{j}}^{\mathrm{K}}{ }^{\mathrm{w}_{\mathrm{j}}} / \mathrm{M}_{\mathrm{j}}}
$$

where: $x_{i}$ is the molar fraction of component $i ; \gamma_{i}$ is the activity coefficient of component $i ; \gamma_{i}^{\mathrm{W}}$ is the corresponding activity coefficient expressed on the mass fraction scale; and $\mathrm{w}_{\mathrm{i}}$ and $\mathrm{M}_{\mathrm{i}}$ are the mass fraction and molar mass, respectively, of component $i$.

Estimation of the NRTL parameters was obtained by an algorithm developed in the FORTRAN programming language. This algorithm uses the modified simplex method applied to the objective function of composition (Equation (8)) to estimate thermodynamic parameters. The procedure for calculation of parameters involves flash calculations for the midpoint composition of the experimental tie lines, according to the procedure developed by Stragevitch and d'Avila (1997).

$$
\mathrm{OF}_{\mathrm{w}}=\sum_{\mathrm{m}}^{\mathrm{D}} \sum_{\mathrm{n}}^{\mathrm{N}} \sum_{\mathrm{i}}^{\mathrm{K}-1}\left[\begin{array}{l}
\left(\frac{\mathrm{w}_{\mathrm{i}, \mathrm{n}, \mathrm{m}}^{\mathrm{I}, \mathrm{exp}}-\mathrm{w}_{\mathrm{i}, \mathrm{n}, \mathrm{m}}^{\mathrm{I}, \mathrm{calc}}}{\sigma_{\mathrm{w}_{\mathrm{i}, \mathrm{n}, \mathrm{m}}^{\mathrm{I}}}}\right)^{2} \\
\left(\frac{\mathrm{w}_{\mathrm{i}, \mathrm{n}, \mathrm{m}}^{\mathrm{II}}-\mathrm{w}_{\mathrm{i}, \mathrm{n}, \mathrm{m}}}{\sigma_{\mathrm{w}_{\mathrm{i}, \mathrm{II}, \mathrm{m}}}}\right)^{2}
\end{array}\right]
$$

where $\mathrm{D}$ is the is the total number of data systems; $\mathrm{N}$ is the total number of tie lines; $\mathrm{K}$ is the total number of components in the data system; $\mathrm{w}$ is the mass fraction; subscripts $\mathrm{i}, \mathrm{n}$ and $\mathrm{m}$ are the component, tie line and system number, respectively; exp and calc represent, respectively, the experimental and calculated composition; and $\sigma$ is the standard deviation observed for the composition of each phase. 
The parameters of the UNIFAC-DRTM model were tested, using the software AspenPlus (Aspen Technology), in the prediction of the LLE of the system composed of glycerol (1) + ethanol (2) + FAEE from fodder radish oil (3).

The average deviations between the experimental and calculated compositions in both phases were calculated according to Equation (9).

$$
\Delta=100 \cdot\left\{\sum_{\mathrm{n}}^{\mathrm{N}} \sum_{\mathrm{i}}^{\mathrm{K}}\left[\begin{array}{l}
\left(\mathrm{w}_{\mathrm{i}, \mathrm{n}}^{\mathrm{I}, \text {exp}}-\mathrm{w}_{\mathrm{i}, \mathrm{n}}^{\mathrm{I}, \text { calc }}\right)^{2}+ \\
\left(\mathrm{w}_{\mathrm{i}, \mathrm{n}}^{\mathrm{II}, \exp }-\mathrm{w}_{\mathrm{i}, \mathrm{n}}^{\mathrm{II}, \text { calc }}\right)^{2}
\end{array}\right]\right\}^{1 / 2}
$$

\section{Simulation and Sensitivity Analyses}

In the simulation of biodiesel purification, only the NRTL binary interaction parameters obtained from experimental data were used. Considering the components glycerol (1), ethanol (2), FAEE from fodder radish oil (3) and water (4), the NRTL binary parameters for component pairs (12), (13) and (23) were obtained from the original experimental data presented in this work; the NRTL binary parameters for component pairs (24) and (34) were readjusted in this work from data presented by Basso et al. (2014); and the NRTL binary parameters for component pair (14) were obtained by Krishna et al. (1989).

The simulation was performed considering a complete conversion of triacylglycerols to fatty acids ethyl esters, with no production of residual soaps, intending to remove the excess of ethanol and residual glycerol. This approach was used because systems containing FAEE + ethanol + glycerol or water are the most common systems formed in ethyl biodiesel production, regardless of the raw material, process and catalyst (enzymes, chemical homogeneous or chemical heterogeneous) used. In addition, there is a technical impossibility to obtain LLE experimental data, including individual partitioning of ethyl esters, and to adjust all binary interaction parameters for the NRTL model considering each minority compound possibly formed in biodiesel production.

The sensitivity analyses were performed using the simulation software AspenPlus (Aspen Technology), always considering a final molar ratio between glycerol:FAEE of 1:3 immediately after transesterification. In those analyses, three different flowsheets for biodiesel water washing were simulated, as shown in Figure 1. In all simulations, the first settler (SETA) was dedicated to separation of the glycerol-rich stream, a step common to the three propositions. In the first proposition, the biodiesel water washing step is composed of only one mixer/settler unit, MIX-B and SET-B in Flowsheet I. In the second proposition, one more mixer/settler unit (MIX-C and SET-C) was added to the biodiesel washing step, resulting in a purification system with two pure water streams in crosscurrent flow (Flowsheet II). In the last one, two mixer/settler units are utilized in a countercurrent arrangement with the pure water stream (WTR) fed in mixer C (MIX-C). Components $\mathrm{i}=1,2,3$ and 4 correspond, in this order, to glycerol, ethanol, FAEE and water. In the acronym representation, $\mathrm{m}_{\mathrm{i}}^{\text {stx }}$ and $\mathrm{w}_{\mathrm{i}}^{\mathrm{stx}}$ are, respectively, the mass flow and mass fraction of component $i$ in the stream $x$, with the streams named as shown in Figure 1. The requirements of water for biodiesel purification were always presented as a mass ratio to FAEE in the feed stream $\left(\mathrm{M}_{\text {water }} / \mathrm{M}_{3}^{\mathrm{FEED}}\right)$ because this stream was never changed in the different simulations performed, which provided a constant reference value.

In Flowsheet (I), two different processes were simulated. In the glycerol separation step, performed in the SET-A unit, the composition of ethanol and glycerol in the ester-rich stream, respectively $\mathrm{w}_{2}^{\mathrm{EP}-\mathrm{A}}$ and $\mathrm{w}_{1}^{\mathrm{EP}-\mathrm{A}}$, were evaluated as a function of different mass fractions of excess ethanol in the feed stream $\left(\mathrm{w}_{2}^{\mathrm{FEED}}\right)$. In addition, using only one water washing stage, the water mass flow requirement in the stream WTR-B $\left(\mathrm{M}_{\mathrm{WTR}-\mathrm{B}} / \mathrm{M}_{3}^{\mathrm{FEED}}\right)$ to obtain an ethanol mass fraction in the stream EP-B $\left(\mathrm{w}_{2}^{\mathrm{EP}-\mathrm{B}}\right)$ lower than 0.002 (biodiesel standard requirements) was evaluated until $\mathrm{w}_{2}^{\mathrm{FEED}}$ was equal to 0.12 , a value corresponding to 3 moles of excess ethanol from a previous hypothetical transesterification reaction.

In Flowsheet (II), taking into account a crosscurrent water washing process performed in two stages and 3 moles of excess ethanol from the transesterification reaction, the water mass flow requirement in stream WTR-C was evaluated as a function of the water mass flow requirement in stream WTR-B to obtain $\mathrm{w}_{2}^{\mathrm{EP}-\mathrm{C}}$ lower than 0.002. Similarly, the total water mass flow, given by the sum of water mass flows in streams WTR-B and WTR-C, was evaluated as a function of $\mathrm{M}_{\mathrm{WTR}-\mathrm{B}} / \mathrm{M}_{3}^{\mathrm{FEED}}$ to achieve $\mathrm{w}_{2}^{\mathrm{EP}-\mathrm{C}}$ lower than 0.002 , so as to determine the minimum water requirement for biodiesel purification. 


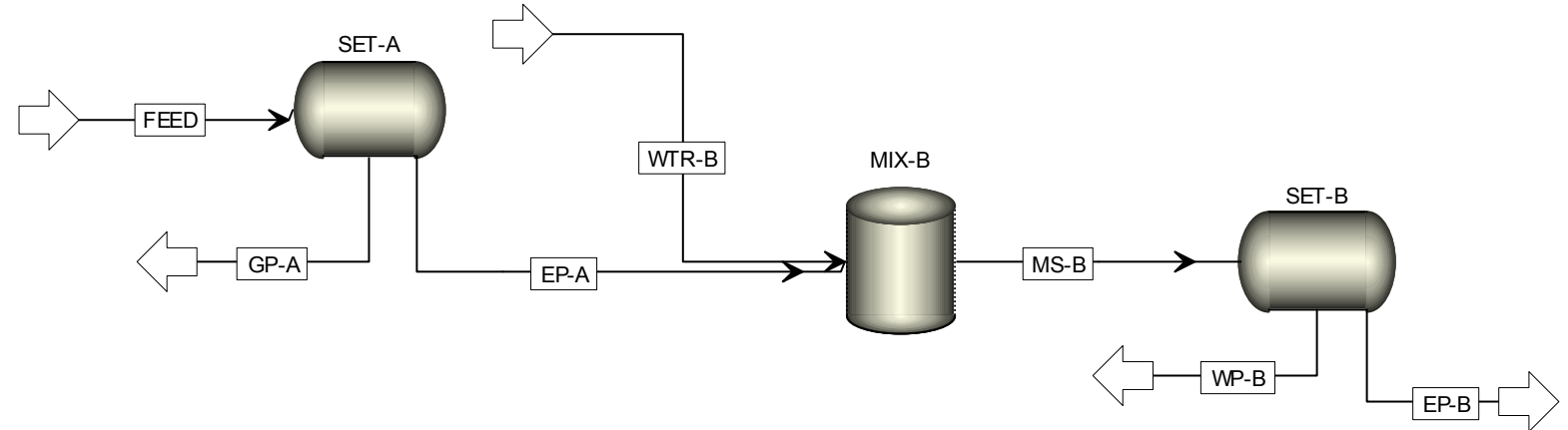

Flowsheet I

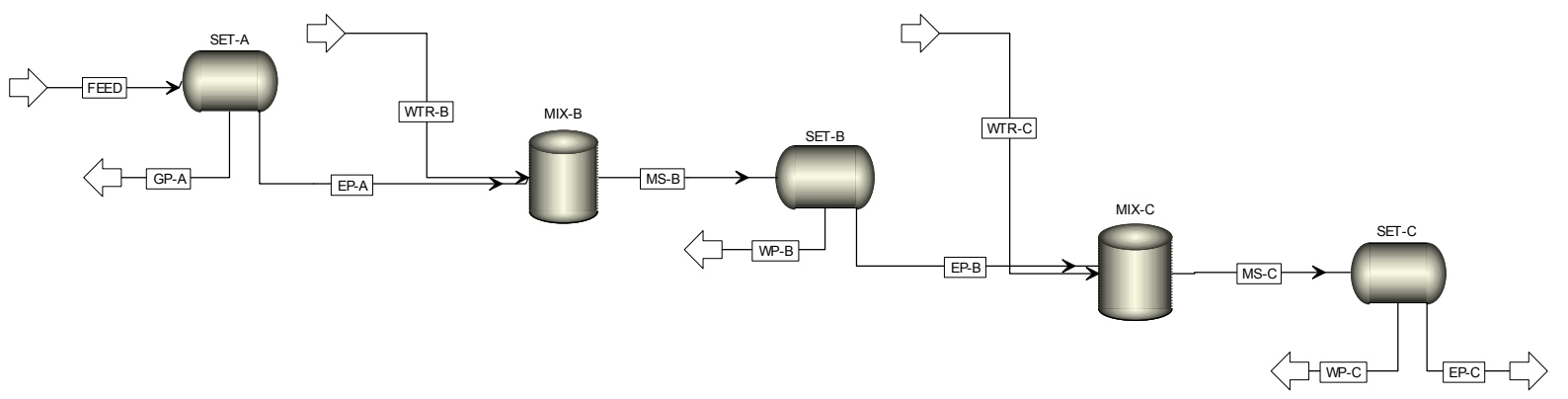

Flowsheet II

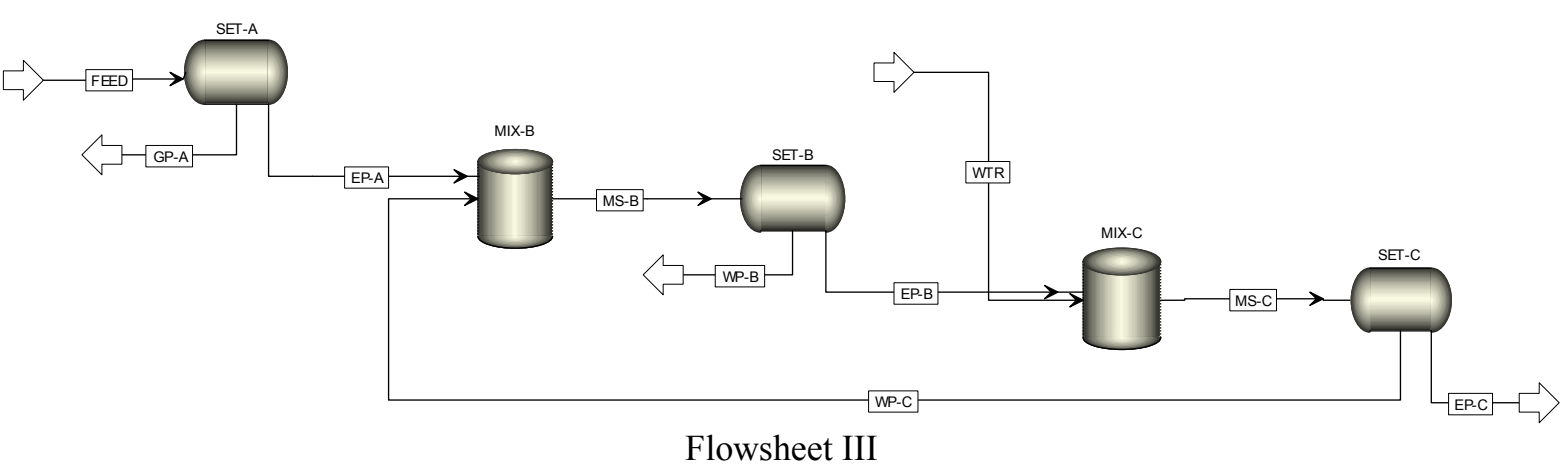

Figure 1: Flowsheets for the Biodiesel Purification Steps: (FEED) products from transesterification reaction; (SET-A) settler for glycerol-rich phase separation; (SET/MIX - B or C) settler/ mixer unit for water washing; (EP) ester-rich phase; (GP) glycerol-rich phase; (WTR) pure water streams.

In Flowsheet (III), considering a countecurrent biodiesel water washing process, the water requirement in stream WTR-C to obtain $\mathrm{w}_{2}^{\mathrm{EP}-\mathrm{C}}$ lower than 0.002 was evaluated as a function of different ethanol contents in the FEED stream until $\mathrm{w}_{2}^{\mathrm{FEED}}$ was equal to 0.12 , so as to quantify the water required for removing different quantities of ethanol until reaching the biodiesel standard requirement. Additionally, decreases of the ethanol mass fraction in stream EP-C $\left(\mathrm{w}_{2}^{\mathrm{EP}-\mathrm{C}}\right)$ as a function of $\mathrm{M}_{\mathrm{WTR}} / \mathrm{M}_{3}^{\mathrm{FEED}}$ were evaluated to estimate how different water contents added to the process affect ethanol removal from the system under study.

\section{RESULTS AND DISCUSSION}

Biodiesel from fodder radish oil is characterized by ethyl oleate $\left(\mathrm{C}_{20} \mathrm{H}_{38} \mathrm{O}_{2}\right)$ as the main ester and large quantities of ethyl linoleate $\left(\mathrm{C}_{20} \mathrm{H}_{36} \mathrm{O}_{2}\right)$, ethyl linolenate $\left(\mathrm{C}_{20} \mathrm{H}_{34} \mathrm{O}_{2}\right)$, eicosenoic acid ethyl ester $\left(\mathrm{C}_{22} \mathrm{H}_{42} \mathrm{O}_{2}\right)$ and ethyl erucate $\left(\mathrm{C}_{24} \mathrm{H}_{46} \mathrm{O}_{2}\right)$, as shown in Table 1. Its composition is very heterogeneous, containing ethyl esters with up to eight carbon atoms of difference and presenting more than $70 \%$ of saturated or monounsaturated esters. This ester profile showed lower values of diunsaturated and triunsaturated esters compared to those found for biodiesel from soybean and sunflower oils, two important vegetable oils 
produced worldwide, resulting in a biodiesel with good oxidative stability. In addition, the saturated ester content lower than $10 \%$ allows the use of biodiesel at low temperatures since there is no formation of solid material as in biofuels with high contents of saturated esters like those produced from palm, babassu and coconut oils.

From the ester composition, the average molar mass of FAEE from fodder radish oil was 316.63 $\mathrm{g} \cdot \mathrm{mol}^{-1}$ and rounded to a hypothetical molecule with molar mass of $310.52 \mathrm{~g} \cdot \mathrm{mol}^{-1}$.

Table 2 shows the individual ethyl ester composition in each phase per tie line. The maximum deviation between the average molar mass of FAEE per tie line and the hypothetical molecule molar mass was
$1.46 \%$. This lower deviation indicates adequacy of the pseudo-component approach for this system, since there was not a considerable difference in the individual partition of ethyl esters between GP and EP. This approach allows for modeling of the LLE of this type of system by NRTL, or other molecular model, since it is possible to reduce the number of parameters to be adjusted.

The LLE data for the pseudo-ternary system glycerol (1) + ethanol (2) + FAEE from fodder radish oil (3) are shown in Table 3. The maximum deviation in mass balance per tie line is $0.45 \%$, with average deviation equal to $0.19 \%$. This low deviation indicates the good quality of experimental data, since the total mass measured in the overall composition was very similar to the sum of the calculated masses of the phases.

Table 1: Ethyl ester composition of FAEE from fodder radish oil in mass percentage.

\begin{tabular}{|c|c|c|c|c|}
\hline $\begin{array}{l}\text { Fatty acid group } \\
\text { in ethyl ester }\end{array}$ & $\begin{array}{l}\text { Molecular } \\
\text { formula }\end{array}$ & Ethyl ester & $\mathrm{MM}\left(\mathrm{g} \cdot \mathrm{mol}^{-1}\right)$ & $100 w^{a}$ \\
\hline $\mathrm{c} 16: 0$ & $\mathrm{C}_{18} \mathrm{H}_{36} \mathrm{O}_{2}$ & Hexadecanoic acid ethyl ester & 284.48 & 5.47 \\
\hline c18:0 & $\mathrm{C}_{20} \mathrm{H}_{40} \mathrm{O}_{2}$ & Octadecanoic acid ethyl ester & 312.53 & 2.48 \\
\hline c18:1 & $\mathrm{C}_{20} \mathrm{H}_{38} \mathrm{O}_{2}$ & cis-9-Octadecenoic acid ethyl ester & 310.51 & 40.89 \\
\hline $\mathrm{c} 18: 2$ & $\mathrm{C}_{20} \mathrm{H}_{36} \mathrm{O}_{2}$ & cis-9, cis-12-Octadecadienoic acid ethyl ester & 308.50 & 16.89 \\
\hline $\mathrm{c} 18: 3$ & $\mathrm{C}_{20} \mathrm{H}_{34} \mathrm{O}_{2}$ & $\begin{array}{l}\text { cis- } 9 \text {, cis- } 12 \text {, cis- } 15 \text {-Octadecatrienoic acid } \\
\text { ethyl ester esteester }\end{array}$ & 306.48 & 11.99 \\
\hline c20:0 & $\mathrm{C}_{22} \mathrm{H}_{44} \mathrm{O}_{2}$ & Icosanoate acid ethyl ester & 340.58 & 0.87 \\
\hline c20:1 & $\mathrm{C}_{22} \mathrm{H}_{42} \mathrm{O}_{2}$ & cis-11-Icosenoic acid ethyl ester & 338.57 & 10.13 \\
\hline c22:1 & $\mathrm{C}_{24} \mathrm{H}_{46} \mathrm{O}_{2}$ & cis-13-Docosenoic acid ethyl ester & 366.62 & 10.59 \\
\hline c24:1 & $\mathrm{C}_{26} \mathrm{H}_{50} \mathrm{O}_{2}$ & cis-15-Tetracosenoic acid ethyl ester & 394.67 & 0.69 \\
\hline
\end{tabular}

${ }^{a}$ mass fraction of ethyl ester

Table 2: Individual fatty acid ethyl ester composition per tie line in each phase at $T=298.2 \mathrm{~K}$.

\begin{tabular}{|c|c|c|c|c|c|c|c|c|c|c|}
\hline $\begin{array}{c}\mathrm{C}_{18} \mathrm{H}_{36} \mathrm{O}_{2} \\
100 w^{c}\end{array}$ & $\begin{array}{c}\mathrm{C}_{20} \mathrm{H}_{40} \mathrm{O}_{2} \\
100 \mathrm{w}^{\mathrm{c}}\end{array}$ & $\begin{array}{c}\mathrm{C}_{20} \mathrm{H}_{38} \mathrm{O}_{2} \\
100 w^{\mathrm{c}}\end{array}$ & $\begin{array}{c}\mathrm{C}_{20} \mathrm{H}_{36} \mathrm{O}_{2} \\
100 w^{\mathrm{c}}\end{array}$ & $\begin{array}{c}\mathrm{C}_{20} \mathrm{H}_{34} \mathrm{O}_{2} \\
100 w^{\mathrm{c}}\end{array}$ & $\begin{array}{c}\mathrm{C}_{22} \mathrm{H}_{44} \mathrm{O}_{2} \\
100 w^{\mathrm{c}}\end{array}$ & $\begin{array}{c}\mathrm{C}_{22} \mathrm{H}_{42} \mathrm{O}_{2} \\
100 w^{\mathrm{c}}\end{array}$ & $\begin{array}{c}\mathrm{C}_{24} \mathrm{H}_{46} \mathrm{O}_{2} \\
100 w^{\mathrm{c}}\end{array}$ & $\begin{array}{c}\mathrm{C}_{26} \mathrm{H}_{50} \mathrm{O}_{2} \\
100 w^{\mathrm{c}}\end{array}$ & $\frac{\mathrm{MM}}{\left(\mathrm{g} \cdot \mathrm{mol}^{-1}\right)}$ & $\mathrm{d}(\%)^{\mathrm{b}}$ \\
\hline \multicolumn{11}{|c|}{ glycerol-rich phase } \\
\hline 5.61 & 2.21 & 41.29 & 18.38 & 13.80 & 0.70 & 9.19 & 8.37 & 0.45 & 314.92 & 0.54 \\
\hline 5.88 & 1.96 & 41.27 & 20.10 & 16.52 & 0.45 & 7.75 & 5.73 & 0.33 & 312.88 & 1.19 \\
\hline 5.96 & 1.81 & 40.81 & 20.80 & 17.62 & 0.34 & 7.17 & 5.22 & 0.26 & 312.32 & 1.36 \\
\hline 5.86 & 1.69 & 38.72 & 21.00 & 20.69 & 0.28 & 6.12 & 3.98 & 1.66 & 312.26 & 1.38 \\
\hline 6.33 & 1.48 & 38.33 & 22.08 & 19.06 & 0.61 & 5.84 & 5.77 & 0.49 & 312.26 & 1.38 \\
\hline 5.50 & 1.26 & 37.83 & 21.43 & 21.55 & 0.08 & 7.29 & 4.89 & 0.18 & 312.01 & 1.46 \\
\hline \multicolumn{11}{|c|}{ ester-rich phase } \\
\hline 5.36 & 2.45 & 40.85 & 16.77 & 11.74 & 0.89 & 10.34 & 10.92 & 0.67 & 316.89 & 0.08 \\
\hline 5.28 & 2.42 & 40.65 & 16.79 & 12.03 & 0.88 & 10.25 & 10.77 & 0.91 & 316.96 & 0.11 \\
\hline 5.31 & 2.41 & 40.63 & 16.81 & 12.04 & 0.89 & 10.25 & 10.85 & 0.81 & 316.92 & 0.09 \\
\hline 5.31 & 2.40 & 40.71 & 16.91 & 12.15 & 0.86 & 10.20 & 10.72 & 0.75 & 316.79 & 0.05 \\
\hline 5.34 & 2.39 & 40.71 & 16.90 & 12.07 & 0.87 & 10.31 & 10.75 & 0.65 & 316.76 & 0.04 \\
\hline 5.40 & 2.40 & 40.69 & 17.04 & 12.29 & 0.85 & 10.13 & 10.54 & 0.65 & 316.58 & 0.02 \\
\hline
\end{tabular}

${ }^{a}$ average molar mass of FAEE per tie line in each phase

${ }^{\mathrm{b}}$ deviation, per tie line, between FAEE average molar mass and pseudo-molecule molar mass

${ }^{\mathrm{c}}$ mass fraction of ethyl ester 
Table 3: Liquid-liquid equilibrium data for the pseudo-ternary system glycerol (1) + ethanol (2) + FAEE from fodder radish oil (3), at $298.2 \mathrm{~K}^{\mathrm{a}}$.

\begin{tabular}{|c|c|c|c|c|c|c|c|c|c|}
\hline \multicolumn{3}{|c|}{ Overall composition } & \multicolumn{3}{|c|}{ Ester-rich phase } & \multicolumn{3}{|c|}{ Glycerol-rich phase } & \multirow{2}{*}{$\delta(\%)^{b}$} \\
\hline $100 \mathrm{~W}_{1}{ }^{\mathrm{c}}$ & $100 \mathrm{w}_{2}{ }^{\mathrm{c}}$ & $100 \mathrm{w}_{3}{ }^{\mathrm{c}}$ & $100 \mathrm{~W}_{1}{ }^{\mathrm{c}}$ & $100 \mathrm{w}_{2}$ & $100 \mathrm{w}_{3} 3^{\mathrm{c}}$ & $100 \mathrm{w}_{1}{ }^{\mathrm{c}}$ & $100 \mathrm{w}_{2}{ }^{\mathrm{c}}$ & $100 w^{c}$ & \\
\hline 15.29 & 44.86 & 39.85 & 3.58 & 32.31 & 64.11 & 26.59 & 59.33 & 14.08 & 0.45 \\
\hline 21.14 & 38.89 & 39.97 & 0.93 & 24.36 & 74.71 & 41.21 & 54.06 & 4.73 & 0.11 \\
\hline 23.39 & 34.68 & 41.93 & 1.10 & 18.54 & 80.36 & 47.14 & 50.17 & 2.69 & 0.13 \\
\hline 29.49 & 29.53 & 40.98 & 0.44 & 15.82 & 83.74 & 55.86 & 43.03 & 1.11 & 0.02 \\
\hline 35.09 & 24.42 & 40.49 & 0.74 & 10.31 & 88.95 & 64.74 & 34.77 & 0.49 & 0.30 \\
\hline 39.67 & 19.65 & 40.68 & 0.68 & 8.28 & 91.04 & 71.46 & 28.34 & 0.20 & 0.15 \\
\hline
\end{tabular}

a the maximum combined uncertainty $\left(u_{c}\right)$ calculated using Equation (4) was 0.0206

${ }^{\mathrm{b}}$ mass balance deviation per tie line calculated according to Equation (2)

${ }^{c}$ mass fraction of ethyl ester

The adjusted/readjusted NRTL parameters used in all simulations are presented in Table 4 . NRTL binary interaction parameters for the components water and glycerol were obtained directly from the literature (Krishna et al., 1989). Average deviation between experimental and calculated values for readjustment of the NRTL binary parameters for the system ethanol (2) + FAEE from fodder radish oil (3) + water (4), presented by Basso et al. (2014), calculated according to Equation (9) was $1.22 \%$, and the maximum deviation per tie line was $2.35 \%$, showing a proper description of the experimental data by the molecular thermodynamic model.

Table 4: Liquid-liquid equilibrium NRTL parameters.

\begin{tabular}{|c|c|c|c|}
\hline \multicolumn{3}{|c|}{ NRTL } \\
\hline pair $^{\mathbf{a}}$ & $\mathbf{A}(\mathbf{0}) \mathbf{i j} / \mathbf{K}$ & $\mathbf{A}(\mathbf{0}) \mathbf{j i} / \mathbf{K}$ & $\boldsymbol{\alpha} \mathbf{( 0 )} \mathbf{i j}=\boldsymbol{\alpha}(\mathbf{0}) \mathbf{j i}$ \\
\hline 12 & 412.1500 & 0.5564 & 0.1000 \\
13 & 3799.4000 & 2912.9000 & 0.1000 \\
$14^{\mathrm{b}}$ & $-385.5100^{\mathrm{b}}$ & $-453.1800^{\mathrm{b}}$ & $0.2000^{\mathrm{b}}$ \\
23 & 291.1200 & 225.6800 & 0.5552 \\
24 & 440.7000 & -104.6800 & 0.1000 \\
34 & 778.4000 & 4969.7000 & 0.1000 \\
\hline
\end{tabular}

${ }^{\text {a }}$ glycerol (1), ethanol (2), FAEE from fodder radish oil (3), water (4)

${ }^{\mathrm{b}}$ binary parameters obtained from the literature (Krishna et al. 1989).

The average deviation between experimental and calculated values using the NRTL model for the system glycerol (1) + ethanol (2) + FAEE from fodder radish oil (3), calculated according to Equation (9), was $0.97 \%$, and the maximum deviation per tie line was $1.48 \%$. Both tie lines with high ethanol composition presented higher deviation with the NRTL model, underestimating the FAEE content in GP, while the deviations for other tie lines were less than $0.91 \%$. It can be observed from Figure 2 that the thermodynamic model underestimated ethanol composition in the GP close to the plait point, describing a slightly smaller phase separation region than that indicated by the experimental data.
The miscibility between FAEE and glycerol is very low, showing strong dependence of the ethanol mass fraction on the overall composition. Ethanol is distributed in both phases, having greater affinity for the glycerol-rich one, as shown for the tie line slopes.

In spite of the characteristic and heterogeneous composition of FAEE from fodder radish oil, there is no considerable difference between the LLE behavior of this system and those containing glycerol + ethanol + FAEE from macauba pulp or crambe oils (Basso et al., 2012; Basso et al., 2013). This similarity is observed for the maximum ethanol content allowing phase splitting (about $60 \%$ ), the tendencies of tie lines slopes, the biphasic region, the composition of the calculated plait points and the low difference among the individual ester distributions between the phases. These characteristics indicate a similar behavior for the glycerol settling step during the production of these biofuels. In addition to these works, Oliveira et al. (2011) also obtained similar LLE behavior for the maximum ethanol mass fraction, tendencies for tie line slope and biphasic separation region, studying systems composed of glycerol + ethanol + ethyl biodiesel from canola oil.

Although data for the LLE of systems containing methanol + glycerol + esters from fodder radish oil are scarce, it is possible to compare the effect of alcohol type used in the study of LLE behavior for other biodiesels and/or esters. Studying LLE behavior of systems composed of glycerol + biodiesel from soybean oil + methanol or ethanol, da Silva et al. (2013) reported a larger phase separation region for the system containing methanol at the same temperature. Comparing the data obtained by Andreatta et al. (2008) and Andreatta (2012) studying the LLE of systems composed of glycerol + methyl oleate + methanol or ethanol, respectively, at $333 \mathrm{~K}$, a larger biphasic region was also observed for the system containing methanol. This behavior probably could be associated with the higher polarity of methanol compared to 
ethanol, resulting in lower affinity for the alkyl esters, especially when glycerol is present in the systems.

The greater miscibility between ethanol and FAEE compared to methanol, observed from the lower biphasic region, hampers the glycerol settling step because there is excess ethanol at the transesterification offset. On the other hand, the miscibility of ethanol with vegetable oils is greater than methanol, promoting better contact between those compounds at the initial stages of the transesterification reaction and, consequently, favoring the reaction onset.

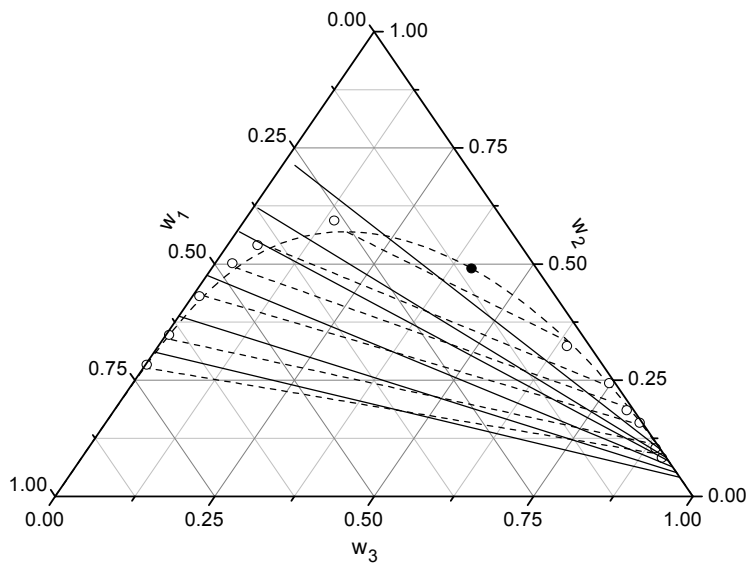

Figure 2: Liquid-liquid equilibrium diagram for the system glycerol (1) + ethanol (2) + FAEE from fodder radish oil (3) at $\mathrm{T}=298.2 \mathrm{~K}: \mathrm{w}$ is the mass fraction of the component; ( $($ ) experimental data; (-) UNIFACDRTM; (•) NRTL calculated plait point; (---) NRTL.

Deviations between experimental data and UNIFAC-DRTM calculated values ranged from 1.3\% and $6.2 \%$, with the higher deviations at high ethanol contents (Figure 2). The region of phase separation was greatly overestimated by the model. Ethanol mass fractions were overestimated in GP, mainly in the region near the plait point, with high ethanol content, and underestimated in EP. The average deviation between experimental and calculated mass fractions was $3.6 \%$, higher than $2.8 \%$ obtained at the same temperature for the system containing FAEE from macauba pulp oil (Basso et al., 2013). From these results, it is possible to state that UNIFAC-DRTM predicts improperly the LLE of ethyl biodiesels in their purification steps. In this way, simulation of these steps in biodiesel production must be judiciously evaluated due to the high deviations obtained when compared to the molecular models using adjusted parameters.

In the first settling step of biodiesel purification, when glycerol is separated from the system, the relation between ethanol mass fraction in the FEED stream $\left(\mathrm{w}_{2}^{\mathrm{FEED}}\right)$ and in the EP-A stream $\left(\mathrm{w}_{2}^{\mathrm{EP}-\mathrm{A}}\right)$ showed almost linear behavior, with the ratio between the first and the second values varying from about 0.84 to 1.00, as shown in Figure 3a. On the other hand, the glycerol mass fraction in the EP-A stream $\left(\mathrm{w}_{1}^{\mathrm{EP}-\mathrm{A}}\right)$ showed an exponential reduction with the decrease of $\mathrm{w}_{2}^{\mathrm{FEED}}$. Since ethanol distributes between both phases, when its content increases in the FEED stream there is a proportional increase in the mass fraction of this component in the ester-rich stream, resulting in an almost linear behavior between $\mathrm{w}_{2}^{\text {FEED }}$ and $\mathrm{w}_{2}^{\mathrm{EP}-\mathrm{A}}$. In turn glycerol is immiscible in FAEE, requiring high contents of ethanol for its miscibility in the ester-rich stream and, consequently, resulting in an exponential correlation between $\mathrm{w}_{1}^{\mathrm{EP}-\mathrm{A}}$ and $\mathrm{w}_{2}^{\mathrm{FEED}}$.

When 3 moles of excess ethanol from a previous hypothetical reaction are present in the FEED stream, the $\mathrm{w}_{1}^{\mathrm{EP}-\mathrm{A}}$ is about 0.0007 , higher than the upper limit allowed by the biodiesel standard requirement $(0.02 \%)$. The partial removal of ethanol, by evaporation for example, from the system until $\mathrm{w}_{2}^{\mathrm{FEED}}$ is equal to 0.08 , before an ideal settling step, permits a glycerol content in the ester-rich stream lower than $0.02 \%$, the biodiesel standard requirement, without an additional purification step to remove this component.

The water amount required, given by $\mathrm{M}_{\mathrm{WTR}-\mathrm{A}} / \mathrm{M}_{3}^{\mathrm{FEED}}$, for removing ethanol from stream EP-B to levels lower than $0.2 \%$ (biodiesel standard requirement), has a direct linear relationship with the increase of ethanol in the FEED stream, as observed in Figure $3 \mathrm{~b}$. After the separation of GP by settling (SETA), considering the water washing using one mixer/settler stage (Flowsheet I) and 3 moles of ex-


water requirement for removing ethanol from the EP-B stream to levels lower than $0.2 \%$ is about 2.12 times the mass flow of FAEE from fodder radish in the FEED stream.

In the water washing step, taking into account 3 moles of excess ethanol in the FEED stream, and using two sets of mixer/settler units in crosscurrent with two water streams (Flowsheet II), the decreasing of the water requirement in stream WTR-C, $\left(\mathrm{M}_{\mathrm{WTR}-\mathrm{C}} / \mathrm{M}_{3}^{\mathrm{FEED}}\right)$ as a function of the water used in stream WTR-B $\left(\mathrm{M}_{\mathrm{WTR}-\mathrm{B}} / \mathrm{M}_{3}^{\mathrm{FEED}}\right)$ to achieve $0.2 \%$ of ethanol in the EP-C stream, showed a parabolic behavior, as described in Figure 4. This behavior is due to the sum effect characteristic of the crosscurrent configuration because an increase in water used in WTR-B results in a decrease in the water 
required in WTR-C for the reduction of the ethanol content in the ester-rich stream. The minimum water requirement to achieve $0.2 \%$ of ethanol in EP-C occurred using similar ratios of $\mathrm{M}_{\mathrm{WTR}-\mathrm{B}} / \mathrm{M}_{3}^{\mathrm{FEED}}$ and $\mathrm{M}_{\mathrm{WTR}-\mathrm{C}} / \mathrm{M}_{3}^{\mathrm{FEED}}$, equal to 0.249 and 0.259 , respectively. Thus, the use of two sets of mixer/settler units in the crosscurrent assembly resulted in a total water use of about $51 \%$ of the biodiesel mass in the feed stream and one quarter of that used in the single stage mixer/settler to achieve similar biodiesel purity.

According to Figure 5a, the water requirement $\left(\mathrm{M}_{\mathrm{WTR}} / \mathrm{M}_{3}^{\mathrm{FEED}}\right)$ as a function of $\mathrm{w}_{2}^{\mathrm{FEED}}$ to remove ethanol from the EP-C stream to levels lower than $0.2 \%$ using two mixer/settler units in countercurrent

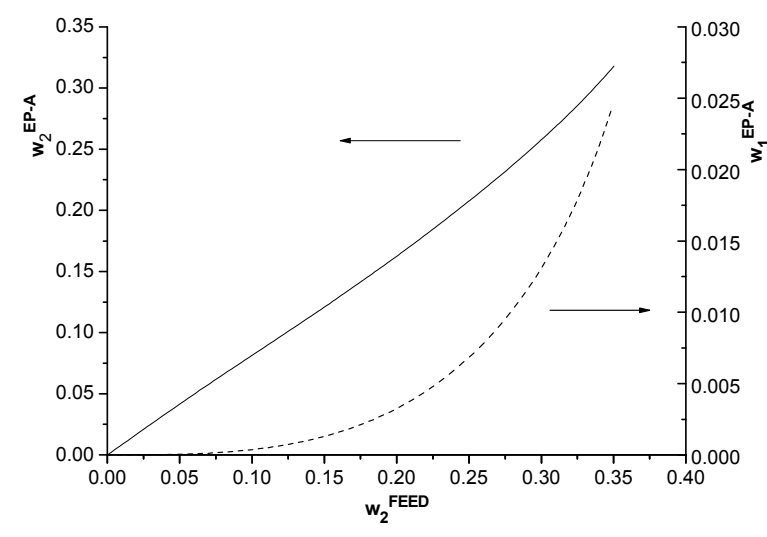

(a)
(Flowsheet III) has a logarithmic behavior, different from the one mixer/settler stage (Flowsheet I) that has a linear behavior. When 3 moles of excess ethanol are present in the FEED stream, the ratio $\mathrm{M}_{\mathrm{WTR}} / \mathrm{M}_{3}^{\mathrm{FEED}}$ required to remove ethanol from the system to an ethanol content in EP-C lower than that specified in the biodiesel standard requirements was about 0.27 , almost half of the total water mass flow used in the crosscurrent flowsheet. In the countercurrent purification process, the water content in the last biodiesel-rich stream (EP-C), was lower than $0.02 \%$, also meeting the biodiesel standard requirement. The decrease of $\mathrm{w}_{2}^{\mathrm{EP}-\mathrm{C}}$ as a function of $\mathrm{M}_{\mathrm{WTR}} / \mathrm{M}_{3}^{\mathrm{FEED}}$ presented a parabolic behavior, according to that shown in Figure 5b.

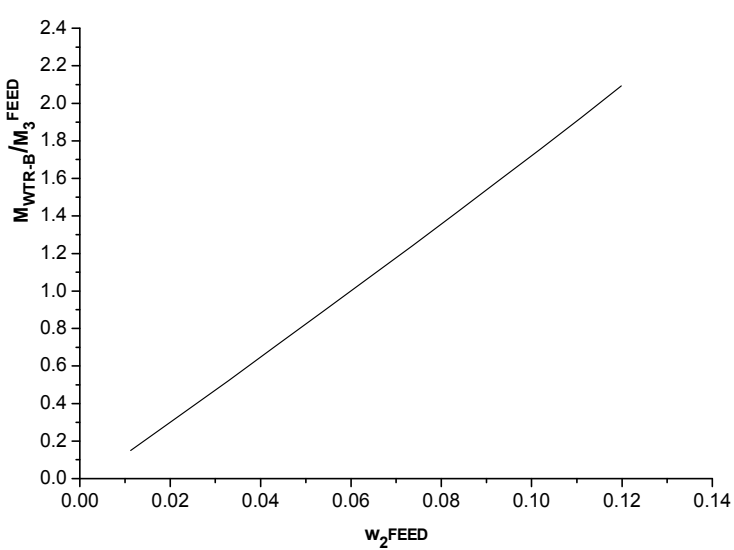

(b)

Figure 3: Flowsheet I: (a): (-) $\mathrm{w}_{2}$ and (---) $\mathrm{w}_{1}$ in stream EP-A as function of $\mathrm{w}_{2}$ in the FEED stream; (b): $(-)$ water mass flow requirement $\left(\mathrm{M}_{\mathrm{WTR}-\mathrm{B}} / \mathrm{M}_{3}^{\mathrm{FEED}}\right)$ to achieve $\left(\mathrm{w}_{2}^{\mathrm{EP}-\mathrm{B}}\right)$ lower than $0.2 \%$ as function of $\mathrm{w}_{2}$ in the FEED stream.

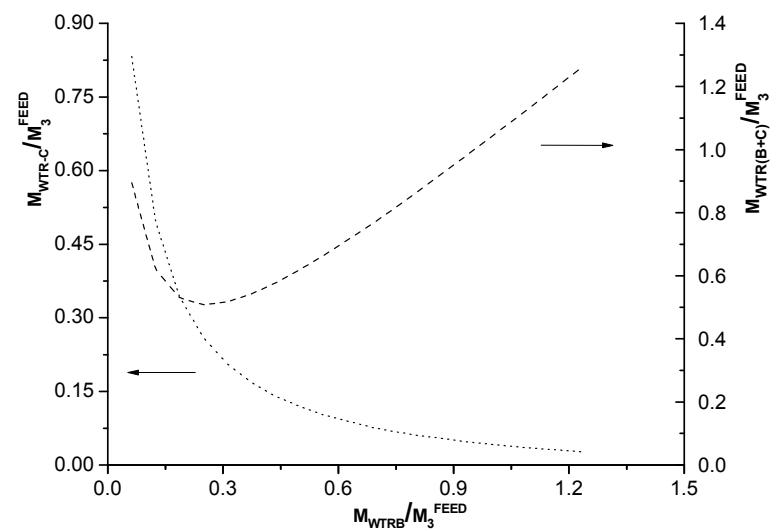

Figure 4: Flowsheet II: (...) $\mathrm{M}_{\mathrm{WTR}-\mathrm{C}} / \mathrm{M}_{3}^{\mathrm{FEED}}$ as a function of $\mathrm{M}_{\mathrm{WTR}-\mathrm{B}} / \mathrm{M}_{3}^{\mathrm{FEED}}$ to obtain $\mathrm{w}_{2}$ in stream EP-C lower than $0.2 \%$; (---) $\mathrm{M}_{\mathrm{WTR}(\mathrm{B}+\mathrm{C})} / \mathrm{M}_{3}^{\mathrm{FEED}}$ as a function of $\mathrm{M}_{\mathrm{WTR}-\mathrm{B}} / \mathrm{M}_{3}^{\mathrm{FEED}}$ to obtain $\mathrm{W}_{2}$ in stream EP-C lower than $0.2 \%$. 


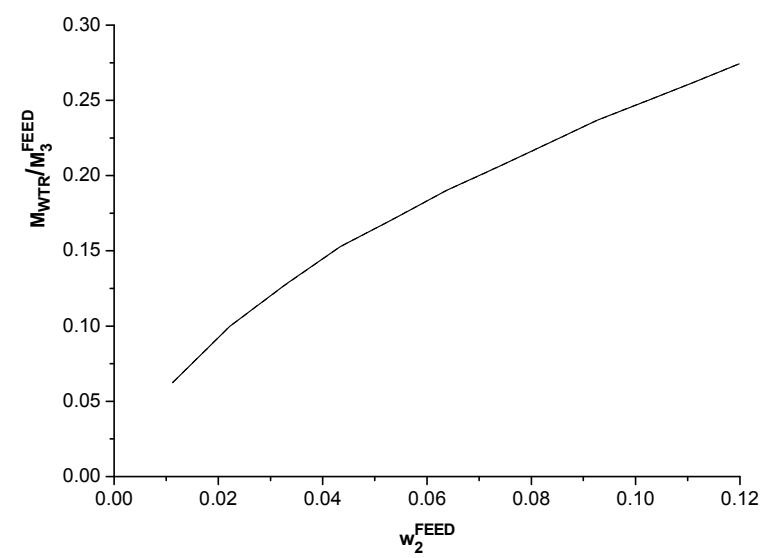

(a)

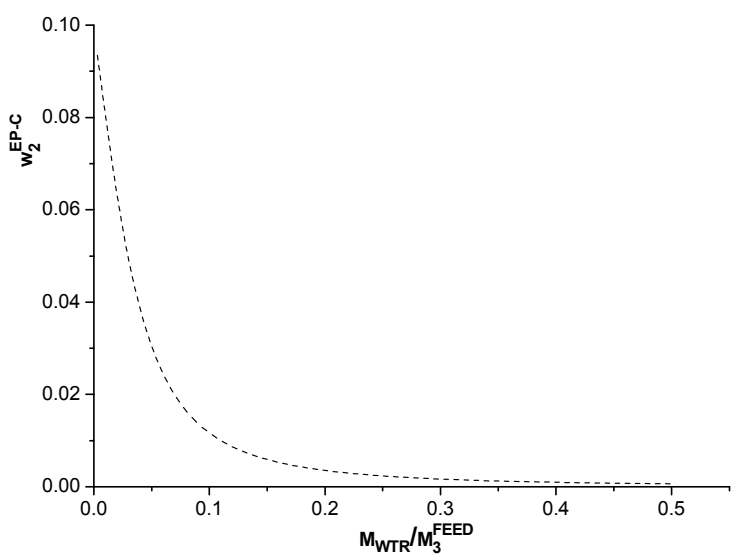

(b)

Figure 5: Flowsheet III: (a) (-) $\mathrm{M}_{\mathrm{WTR}} / \mathrm{M}_{3}^{\mathrm{FEED}}$ as a function of $\mathrm{w}_{2}$ in FEED stream to obtain $\mathrm{w}_{2}$ in stream EP-C lower than $0.2 \%$; (b) (---) $\mathrm{w}_{2}$ in stream EP-C as a function of $\mathrm{M}_{\mathrm{WTR}} / \mathrm{M}_{3}^{\mathrm{FEED}}$.

Although processes using two stages need greater initial investments due to the costs with equipment and industrial piping, the advantages in terms of water savings for the countercurrent flowsheet, using less than one eighth $(0.27 / 2.12)$ of the water required for the one-stage flowsheet, makes this process economically and ecologically very interesting.

The LLE behavior of the systems composed of ethanol + water + FAEE from fodder radish oil presented great similarity with those containing FAEE from macauba pulp or crambe oil at $298 \mathrm{~K}$, according to data reported by Basso et al. (2014). Because the glycerol content is low (0.0007 in mass fraction) after the first settling step, the results of sensitivity analysis of the biodiesel washing step can be correlated to the LLE behavior of systems composed only of ethanol + water + FAEE. Considering the similarity among the LLE behavior of the systems related to the glycerol decanting step (glycerol + ethanol + FAEE) and biodiesel washing step (water + ethanol + FAEE) for biodiesels from macauba pulp, crambe and fodder radish oils, it is possible to assume that the results of the sensitivity analyses performed for the set of systems containing the three biodiesels would be relatively similar.

The results obtained in this work are also useful for the study of the purification steps of other systems composed of glycerol + ethanol + FAEE and of water + ethanol + FAEE presenting similar LLE behavior.

\section{CONCLUSIONS}

The individual distribution of fatty acid ethyl esters is similar in EP and GP with maximum deviation of $1.46 \%$. The NRTL model properly described the system containing glycerol, with adeviation less than $1.0 \%$. Partial removal of ethanol from the system until $\mathrm{w}_{2}$ is equal to 0.08 before an ideal settling step allows a glycerol content lower than $0.02 \%$ in the EP, without additional purification. One mixer/settler unit and two mixer/settler units in crosscurrent and countercurrent, after the glycerol removal step, resulted in the minimum water requirement, given by $\mathrm{M}_{\mathrm{wtr}} / \mathrm{M}_{3}^{\text {(st101) }}$ of, respectively, 2.12, 0.51 and 0.27 to achieve the final ethanol and water contents specified by the biodiesel standard requirements. The simulation of biodiesel purification applying sensitivity analysis, using only adjusted parameters, allows for a complete optimization of the steps involved in the process.

\section{ACKNOWLEDGMENTS}

The authors would like to acknowledge the Fundação de Amparo a Pesquisa do Estado de São Paulo (FAPESP - Process 08/56258-8) for its financial support, and the Conselho Nacional de Desenvolvimento Científico e Tecnológico (CNPq - Process 140362/20096 ) for the scholarship.

\section{NOMENCLATURE}

$$
\begin{array}{ll}
\mathrm{A}(0)_{\mathrm{ij} ;} & \text { NRTL binary interaction parameter, (K) } \\
\mathrm{A}(0)_{\mathrm{ji}} & \\
\mathrm{d} & \begin{array}{l}
\text { deviation between FAEE average and } \\
\text { pseudo-molecule molar masses, }(\%)
\end{array} \\
\mathrm{D} & \text { total number of data systems }
\end{array}
$$




\section{Greek Symbols}

$\alpha(0) \quad$ binary nonrandomness parameter

$\delta \quad$ mass balance deviation per tie line, $(\%)$

$\Delta \quad$ average deviation between the experimental and calculated compositions, (\%)

$\gamma_{i} \quad$ mole fraction-scale activity coefficient

$\gamma_{i}^{w} \quad$ mass fraction-scale activity coefficient

$\sigma \quad$ standard deviation composition for each phase

\section{REFERENCES}

Akoh, C. C., Chang, S.W., Lee, G. C., Shaw, J. F., Enzymatic approach to biodiesel production. Journal of Agricultural and Food Chemistry, 55(22), 89959005 (2007).

Andreatta, E. A. Liquid-liquid equilibria in ternary mixtures of methyl oleate + ethanol + glycerol at atmospheric pressure. Industrial \& Engineering Chemistry Research, 51, 9642-9651 (2012).

Andreatta, E. A., Casas, L. M., Hegel, P., Bottini, S. B., Brignole, E. A., Phase equilibria in ternary mixtures of methyl oleate, glycerol, and methanol. Industrial \& Engineering Chemical Research, 47(15), 5157-5164 (2008).

Atadashi, I. M., Aroua, M. K., Abdul-Aziz, A. R., Sulaiman, N. M. N., Refinning technologies for the purification of crude biodiesel. Applied Energy, 88(12), 4239-4251 (2011).

Barreau, A., Brunella, I., Hemptinne, J. C., Coupard, V., Canet, X., Rivollet, F., Measurements of liquidliquid equilibria for a methanol + glycerol + methyl oleate system and prediction using group contribution statistical associating fluid theory. Industrial \& Engineering Chemical Research, 49(12), 5800-5807 (2010).

Basso, R. C., Meirelles, A. J. A., Batista, E. A. C., Liquid-liquid equilibrium of pseudoternary systems containing glycerol + ethanol + ethylic biodiesel from crambe oil (Crambe abyssinica) at $\mathrm{T} / \mathrm{K}$ $=(298.2,318.2,338.2)$ and thermodynamic modeling. Fluid Phase Equilibria, 333, 55-62 (2012).
Basso, R. C., Miiyake, F. H., Meirelles, A. J. A., Batista, E. A. C., Liquid-liquid equilibrium data and thermodynamic modeling, at $\mathrm{T} / \mathrm{K}=298.2$, in the production washing step of ethyl biodiesel from crambe, fodder radish and macauba pulp oil. Fuel, 117, 590-597 (2014).

Basso, R. C., Silva, C. A. S., Sousa, C. O., Meirelles, A. J. A., Batista, E. A. C., LLE experimental data, thermodynamic modeling and sensitivity analysis in the ethyl biodiesel from macauba pulp oil settling step. Bioresource Technology, 131, 468-475 (2013).

Beneti, S. C., Priamo, W. L., Lanza, M., Kunita, M. H., Mazutti, M. A., Cardozo-Filho, L., Oliveira, J. V., Determination of liquid-liquid equilibrium data for biodiesel containing ternary systems using near infrared technique. Brazilian Journal of Chemical Engineering, 30(1), 23-31 (2013).

Berrios, M., Skelton, R. L., Comparison of purification methods for biodiesel. Chemical Engineering Journal, 144(3), 459-465 (2008).

Casas, A., Rodriguez, J. F., del Peso, G. L., Rodriguez, R., Vicente, G., Carrero, A., Liquid-liquid phase equilibria for soybean oil methanolysis: Experimental, modeling and data prediction. Industrial \& Engineering Chemical Research, 53(9), 37313736 (2014).

Crusciol, C. A. C., Lima, R. L., Lima, E. V., Andreotti, M., Moro, E., Marcon, E., Persistência de palhada e liberação de nutrientes do nabo-forrageiro no plantio direto. Pesquisa Agropecuária Brasileira, 40(2), 161-168 (2005). (In Portuguese).

Dias, J. M., Santos, E., Santo, F., Carvalho, F., AlvimFerraz, M. C. M., Almeida, M. F., Study of and ethylic biodiesel integrated process: Rawmaterials, reaction optimization and purification methods. Fuel Processing Technology, 124, 198205 (2014).

Domingos, A. K., Saad, E. B., Wilhelm, H. M., Ramos, L. P., Optimization of the ethanolysis of Raphanus sativus (L. Var.) crude oil applying the response surface methodology. Bioresource Technology, 99(6), 1837-1845, (2008).

Encinar, J. M., Gonzalez, J. F., Rodrigez, J. J., Tejedor, A., Biodiesel fuels from vegetable oils: Transesterification of Cynara Cardunculus L. oils with ethanol. Energy \& Fuels, 16(2), 443-450 (2002).

Fregolente, P. B. L., Maciel, M. R. W., Oliveira, L. S., Removal of water content from biodiesel and diesel fuel using hydrogel adsorbents. Brazilian Journal of Chemical Engineering, 32(4), 895-901 (2015).

Glisic, S. B., Skala, D. U., Design and optimization of purification procedure for biodiesel washing. 
Experimental Data, Thermodynamic Modeling and Sensitivity Analyses for the Purification Steps of Ethyl Biodiesel from Fodder Radish Oil Production 353

Chemical Industry and Chemical Engineering Quarterly, 15(3), 159-168 (2009).

Kanitkar, A., Balasubramanian, S., Lima, M., Boldor, D., A critical comparison of methyl and ethyl esters production from soybean and rice bran oil in the presence of microwaves. Bioresource Technology, 102(17), 7896-7902 (2011).

Krishna, R., Low, C. Y., Newsham, D. M. T., OliveiraFontes, C. G., Paybarah, A., Liquid-liquid equilibrium in the system glycerol-water-acetone at $25^{\circ} \mathrm{C}$. Fluid Phase Equilibria, 45(1), 115-120 (1989).

Lee, M. J., Lo, Y. C., Lin, H. M., Liquid-liquid equilibria for mixtures containing water, methanol, fatty acid methyl esters, and glycerol. Fluid Phase Equilibria, 299(2), 180-190 (2010).

Liu, X., Piao, X., Wang Y., Zhu S., Liquid-liquid equilibrium for systems of (fatty acid ethyl esters + ethanol + soybean oil and fatty acid ethyl esters + ethanol + glycerol). Journal of Chemical and Engineering Data, 53(2), 359-362 (2008).

Lotero, E., Liu, Y., Lopez, D. E., Swannakarn, K., Bruce, D. A., Goodwin-Jr. J. G., Synthesis of biodiesel via acid catalysis. Industrial \& Engineering Chemical Research, 44(14), 5353-5363 (2005).

Marcilla, A., Ruiz, F., Garcia, A. N., Liquid-liquidsolid equilibria of the quaternary system water ethanol - acetone - sodium chloride at $25^{\circ} \mathrm{C}$. Fluid Phase Equilibria, 112(2), 273-289 (1995)

Mesquita, F. M. R., Feitosa, F. X., Sombra, N. E., Santiago-Aguiar, R. S., Sant'Ana, H. B., Liquid-liquid equilibrium for ternary mixtures of biodiesel (soybean or sunflower) + glycerol + ethanol at different temperatures. Journal of Chemical and Engineering Data, 56(11), 4061-4067 (2011).

Oishi, T., Prausnitz, J. M., Estimation of solvent activities in polymer solutions using a group-contribution method. Industrial \& Engineering Chemistry Process Design and Development, 17(3), 333339 (1978).

Oliveira, M. B., Barbedo, S., Solleti, J. L., Carvalho, S. H. V., Queimada, A. J., Coutinho, J. A. P., Liquid-liquid equilibria for the canola oil biodiesel + ethanol + glycerol system. Fuel, 90(8), 2738-2745 (2011).

Piloto-Rodríguez, R., Melo, E. A., Goyos-Pérez, L., Verhelst, S., Conversion of by-products from the vegetable oil industry into biodiesel and its use in internal engines: A Review. Brazilian Journal of Chemical Engineering, 31(2), 287-301 (2014).

Pisarello, M. L., Costa, B. D., Mendow, G., Querini, C. A., Esterification with ethanol to produce bio- diesel from high acid raw materials: Kinectic studies and analysis of secondary reactions. Fuel Processing Technology, 91(9), 1005-1014 (2010).

Rodrigues, C. E. C., Silva, F. A., Marsaioli-Jr. A., Meirelles, A. J. A., Deacidification of Brazil nut and macadamia nut oils by solvent extraction: Liquid-liquid equilibrium data at $298.2 \mathrm{~K}$. Journal of Chemical and Engineering Data, 50(2), 517-523 (2005).

Saleh, J., Dubé, M. A., Tremblay, A. Y., Separation of glycerol from fame using ceramic membranes. Fuel Processing Technology, 92(7), 1305-1310, (2011).

Sawangkeaw, R., Teeravitud, K., Bunyakiat, S., Ngamprasertsith, S., Biofuel production from palm oil with supercritical alcohols: Effects of the alcohol to oil molar ratios on the biofuel chemical composition and properties. Bioresource Technology, 102(22), 10704-10710 (2011).

da Silva, D. I. S., Mafra, M. R., da Silva F. R., Ndiaye, P. M., Ramos, L. P., Cardoso-Filho, L., Corazza, M. L., Liquid-liquid and vapor-liquid equilibrium data for biodiesel reaction-separation systems. Fuel, 108, 269-276 (2013).

Schuchardt, U., Sercheli, R., Vargas, R. M., Transesterification of vegetable oils: a review. Journal of the Brazilian Chemical Society, 9(3), 199-210 (1998).

Stamenkovic, O. S., Velickovic, A. V., Veljkovic, V. B., The production of biodiesel from vegetable oils by ethanolysis: Current state and perspectives. Fuel, 90(11), 3141-3155 (2011).

Stragevitch, L., d'Avila, S. G., Application of a generalized maximum likelihood method in the reduction of multicomponent liquid-liquid equilibrium data. Brazilian Journal of Chemical Engineering, 14(1), 41-52 (1997).

Valle, P., Velez, A., Hegel, P., Mabe, G., Brignole, E. A., Biodiesel production using supercritical alcohols with a non-edible vegetable oil in a batch reactor. The Journal of Supercritical Fluids, 54(1), 61-70 (2010).

Zhang, H., Ding, J., Qiu, Y., Yanli, Q., Zhao, Z., Kinectics of esterification of acidified oil with different alcohols by a cation ion-exchange resin/polyethersulfone hybrid catalytic membrane. Bioresource Technology, 112, 28-33 (2012).

Zhang, Y., Dubé, M. A., McLean, D. D., Kates, M., Biodiesel production from waste cooking oil: 1 . Process design and technological assessment. Bioresource Technology, 89(1), 1-16 (2003). 